\title{
Fine-scale spatial patterns of the Tertiary relict Zelkova abelicea (Ulmaceae) indicate possible processes contributing to its persistence to climate changes
}

\author{
Marta Bosque • Maria-Irene Adamogianni - Michael Bariotakis • \\ Laurence Fazan • Markus Stoffel • Giuseppe Garfi · Joachim Gratzfeld • \\ Gregor Kozlowski · Stergios Pirintsos
}

\begin{abstract}
In this paper, the fine-scale spatial patterns of the Tertiary relict Zelkova abelicea (Lam.) Boiss. were studied (1) to reveal processes that contributed to its persistence to climate changes and (2) to assist future conservation planning, with the purpose of shifting the attention of conservation practitioners from patterns to processes. Results of the fine-scale spatial patterns of $Z$. abelicea indicate that the species tolerates disturbance and/or tracks changes resulting from disturbance in the
\end{abstract}

M. Bosque · M.-I. Adamogianni · M. Bariotakis ·

S. Pirintsos $(\square)$

Department of Biology, University of Crete, P.O.Box 2208,

71409 Heraklion, Greece

e-mail: pirintsos@biology.uoc.gr

M. Bosque

e-mail: martaa.bosque@gmail.com

M.-I. Adamogianni

e-mail: marie-irene17@hotmail.com

M. Bariotakis

e-mail: navaak@gmail.com

L. Fazan · G. Kozlowski

Department of Biology and Botanic Garden, University of

Fribourg, Chemin du Musée 10, 1700 Fribourg, Switzerland e-mail: fazan0@etu.unige.ch

G. Kozlowski

e-mail: gregor.kozlowski@unifr.ch

L. Fazan · M. Stoffel

Climatic Change and Climate Impacts, Institute

for Environmental Sciences, University of Geneva,

Route de Drize 7, 1227 Carouge, Switzerland

e-mail: markus.stoffel@dendrolab.ch range of its distribution through morphological and reproductive plasticity. In addition, our study indicates that $Z$. abelicea populations are conserved in the absence of metapopulation structure and that the species participates in plant-plant interactions through facilitation processes. Hence, the persistence of the species to climate changes seems to be more complicated and multifactorial than a linear and plain view of species survival in climate refugial areas, and therefore calls for a consideration of the processes revealed in this paper in future conservation planning.

\author{
M. Stoffel \\ Dendrolab.ch, Institute of Geological Sciences, University \\ of Bern, Baltzerstrasse 1-3, 3012 Bern, Switzerland \\ G. Garfi \\ Institute of Plant Genetics, National Research Council (CNR), \\ Corso Calatafimi 414, 90129 Palermo, Italy \\ e-mail: giuseppe.garfi@igv.cnr.it \\ J. Gratzfeld \\ Botanic Gardens Conservation International (BGCI), \\ 199 Kew Road, Richmond, Surrey TW9 3BW, UK \\ e-mail: Joachim.Gratzfeld@bgci.org \\ G. Kozlowski \\ Natural History Museum, Chemin du Musée 6, 1700 Fribourg, \\ Switzerland \\ S. Pirintsos \\ Botanical Garden, University of Crete, Gallos Campus, \\ 74100 Rethymnon, Greece
}


Keywords Tertiary relict trees - Fine-scale spatial pattern · Plasticity · Disturbance $\cdot$ Facilitation · Zelkova abelicea

\section{Introduction}

Many extant plant species in current plant communities are millions of years old and therefore have persisted through dramatic changes in global climate, including the Neogene climate fluctuations, the strong climate oscillations during Quaternary, as well as the recent climate changes (Petit et al. 2005). We know little regarding the ecological processes that have allowed them to persist, while a large number of model-based papers has been published on the possible extinction of plant species due to the present climate change (cf. e.g., Thuiller et al. 2005; Malcolm et al. 2006). A majority of these models indicate alarming consequences of climatic change for biodiversity, with some of the worst scenarios postulating extinction rates that would qualify as the sixth mass extinction in the history of earth (Stork 2010; Barnosky et al. 2011; Bellard et al. 2012).

However, in some cases, the persistence of the abovementioned relict species can be at odds with the pessimistic predictions of many model-based analyses of climate-driven range changes (Hampe and Jump 2011). Moreover, species distribution models typically lack the spatial and biological detail required to predict the persistence of populations at the local level (Hampe and Jump 2011; Schwartz 2012). This lack of detail may have significant consequences on model output, even more so as fine-scale biological and landscape characteristics as well as microclimate buffering have been demonstrated to play a central role in species responses to climate change (Thuiller et al. 2008; Randin et al. 2009; Willis and Bhagwat 2009; Barrows and Murphy-Mariscal 2012).

Zelkova abelicea (Lam.) Boiss. is such a relict species (Tertiary relict) that has withstood long-range climate changes and is restricted to the four main mountain ranges in the island of Crete (Greece). Tertiary relict species are defined here (see Denk et al. 2001) as extant species more or less closely related to fossil taxa of different taxonomic ranks (genus, section, species), which had relatively extensive distribution ranges in western Eurasia during different periods of the Cenozoic, but are at present confined to small isolated relict areas.

The species belongs to the genus Zelkova which was widespread in the Cenozoic. Zelkova appears to have been part of humid mesic forests during the Miocene and Pliocene, but the deterioration of Cenozoic warm, moist climates during the Plio-Pleistocene resulted in the extinction of the genus from many areas (Denk et al. 2001; Wang et al. 2001). The oldest fossils attributed to the genus are from the early Cenozoic (i.e., $55 \mathrm{Ma}$ ) of western North America, where the genus is, however, extinct today (Burnham 1986). The genus was widespread in Europe as well; European fossils have mainly been ascribed to one species, Zelkova zelkovifolia (Ung.) Bùzek et Kotl. (=Z. ungeri Kov.). Zelkova in Europe became restricted to refugia as the result of the cold and aridity during the Pleistocene. Refugia, providing suitable habitats during adverse climate periods, appear to have limited species extinction as well as favouring the emergence of new taxa (Médail and Diadema 2009). The genus eventually disappeared from continental Greece during the middle Pleistocene (Van der Wiel and Wijmstra 1987), but persisted longer in central Italy until ca. 31,000 BP (Follieri et al. 1986). The west Eurasian and east Asiatic taxa were probably isolated starting in the middle Miocene as a result of increasing aridity in central Asia (Wang et al. 2001).

In the present paper, we examine the spatial pattern of $Z$. abelicea at a fine scale to (1) investigate processes that could have contributed to the persistence of the species to climate changes and (2) to investigate whether the results of the spatial analysis could be incorporated in future conservation planning, so as to shift the attention of conservation practitioners from spatial patterns to processes (see Stein and Shaw 2013) that is to shift the attention from conservation goals that focus on maintaining particular spatial patterns in order to ensure that representative samples will survive in a specific area to process-oriented goals, which focus on maintaining ecological processes that, in turn, sustain the presence of species in the area.

\section{Materials and methods}

\section{The species}

Zelkova abelicea (Lam.) Boiss. belongs to the elm family (Ulmaceae) is endemic to the island of Crete and is one of the two European representatives of this otherwise Asiatic genus (Fineschi et al. 2002, 2004). Zelkova sicula, rather recently discovered in Sicily (Di Pasquale et al. 1992), is the second Mediterranean species. Besides the two Mediterranean taxa, one species occurs in the Transcaucasian and Hyrcanian regions (Zelkova carpinifolia (Pall.) $\mathrm{K}$. Koch) and three species are found in eastern Asia (Zelkova serrata (Thunb.) Makino, Zelkova schneideriana Hand.Mazz. and Zelkova sinica C. K. Schneider) (Zheng-yi and Raven 2003; Denk and Grimm 2005).

Zelkova abelicea is currently restricted to the four main mountain ranges of Crete (Lefka Ori, Psiloritis-including Kedhros, Dikti and Afendis Kavousi), at an altitudinal range between 900 and 1,700 $\mathrm{m}$ a.s.l. The coordinates of all known populations have recently been recorded 
Fig. 1 Location of the study area in the East Mediterranean Region. Sites of known populations of Z. abelicea are indicated with black dots. Contour line $750 \mathrm{~m}$

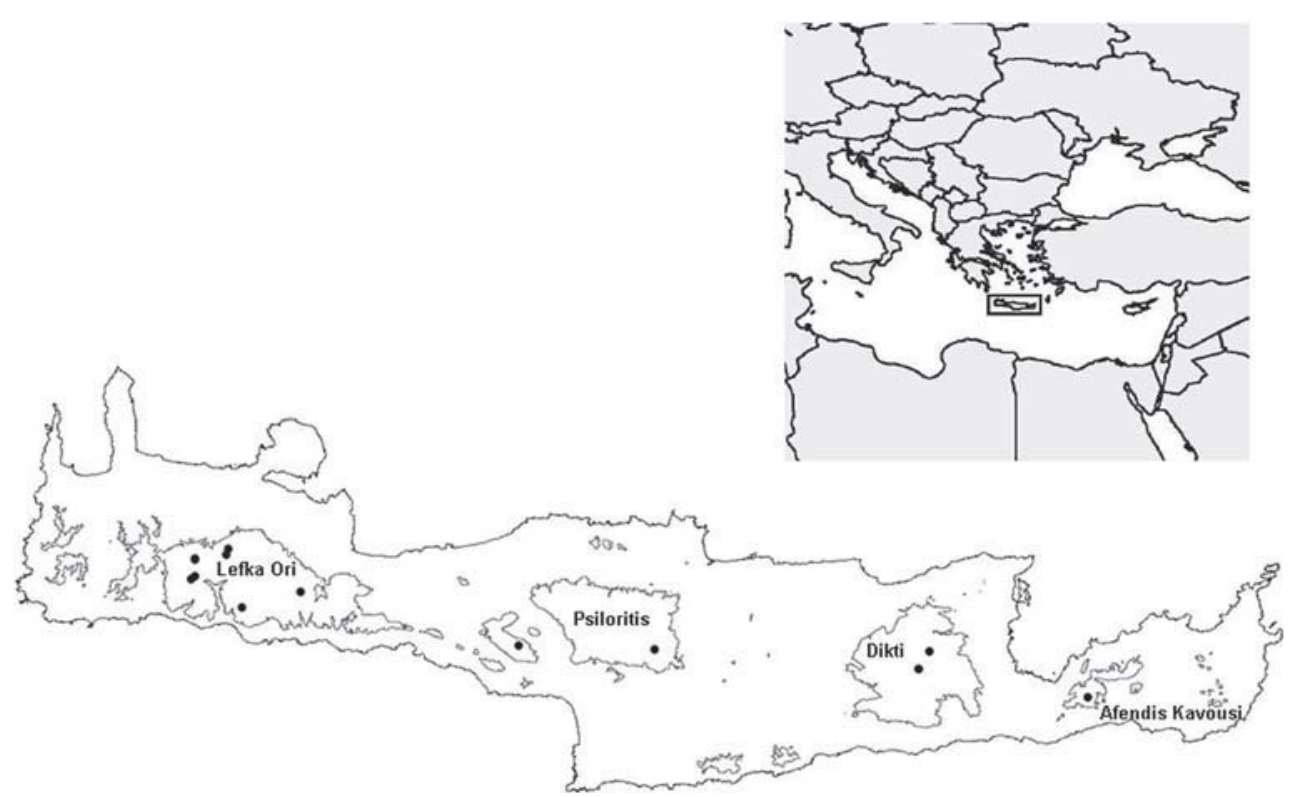

(Kozlowski et al. 2013), and the species has been classified as endangered according to IUCN criteria (Kozlowski et al. 2012).

The study area

Crete is the largest island of Greece and the fifth largest in the Mediterranean Basin, with a total surface of $8,729 \mathrm{~km}^{2}$ and a west-east extension of about $254 \mathrm{~km}$. Being one of the southernmost parts of Europe, it shares the same latitude with central Tunisia.

Calcareous rocks (limestone and dolomites) dominate the mountain terrain, whereas Neogene sediments, including limestones, sandstones and marls, cover large areas of the lowlands, along with ortho-quartzites, phyllites, flyschs, Quaternary rocks and alluvial deposits (Higgins and Higgins 1996).

The climate is Mediterranean with hot, dry summers and mild-to-cool, wet winters. Elevation and longitude have the largest influence on precipitation and yield the highest spatial correlation (positive to elevation and negative to longitude; Vrochidou and Tsanis 2012). Areal mean annual precipitation is estimated to $750 \mathrm{~mm}$ and varies from ca. $440 \mathrm{~mm}$ in the east (Ierapetra; $10 \mathrm{~m}$ a.s.1) to ca. $2,120 \mathrm{~mm}$ in the west (Askifou; $740 \mathrm{~m}$ a.s.1).

According to the NATURA2000 habitats classification scheme (European Commission 2007), Crete is dominated by Sarcopoterium spinosum phryganas, agricultures, Olea and Ceratonia forests, Dehesas, Mediterranean pine forests, Cupressus forests, endemic phryganas of the Euphorbio-Verbascion and endemic oro-Mediterranean heaths.
Data collection

Eleven of the 14 populations of $Z$. abelicea, described by Fazan et al. (2012), have been studied in this contribution; three have been omitted due to access restrictions related to the last heavy winter conditions.

Six populations have been sampled in the Lefka Ori Mountains, one in the Psiloritis Mountains (Rouvas Forest), three populations in the Dikti Mountains and one population in the Thripiti Mountains (see Online Resource 1). More details about the distribution of the island's Zelkova populations are presented in Fig. 1 and in Kozlowski et al. (2013).

For each population, two sampling sites have been selected. Data collection was performed with the line transect method (Elzinga et al. 1998) and included the sampling of one transect of $50 \mathrm{~m}$ per site. The only exception was Dikti Mountains, where 3 sampling sites have been selected for one of the three populations.

In this study, the line transect method was expanded to include detailed patch measurements. In addition to the projection of the canopy of each woody plant species on the line transect and the height of each plant, we performed measurements for each vegetation patch projected on the line transect. For each patch, we (1) recorded all woody species present at the patch (2) measured the maximum canopy length and the height of each woody plant species inside the patch (3) measured the maximum length and width of the patch, as well as the projection of the patch on the line transect. Abundance of species per patch was defined as the ratio of the cumulative projection of the canopies of each woody plant species to the projection of the respective patch on the line transect. 
Conventionally, a distance of $0.5 \mathrm{~m}$ between the aerial parts of two neighboring plants was declared as the threshold beyond which two distinct patches can be identified.

In total, this study includes 268 vegetation patches projected on 23 line transects analyzed in 11 populations. Based on the height of the plants, we divided the records of $Z$. abelicea trees into 5 categories (see Online Resources 2-6 for details): (1) small shrubs (S1) with a height between 0 and $0.5 \mathrm{~m}$; (2) intermediate shrubs (S2) ranging from 0.6 to $1 \mathrm{~m}$; (3) large shrubs (M1) with heights between 1.1 to $2 \mathrm{~m}$; (4) intermediate trees (M2) with heights of 2.1 to $3 \mathrm{~m}$; and (5) large trees (L) being $>3 \mathrm{~m}$ in height (and trespassing $10 \mathrm{~m}$ in several cases).

During fieldwork, we also investigated the occurrence of $Z$. abelicea seedlings and the mode of reproduction of $Z$. abelicea plants at the sampling sites to assess processes related to population turnover. In this regard, historical literature, herbarium records and recent observations covering the last 300 years (1700-2010; Kozlowski et al. 2013) have been used as well. Moreover, co-existing Acer sempervirens L. seedlings were recorded at the study site, annotating their position within and without shrubs and bushes of Z. abelicea.

\section{Data analysis}

A species distribution modeling approach has been applied at a coarser scale $(0.6 \times 0.6 \mathrm{~km})$ to explore whether the current distribution of $Z$. abelicea fits the predictions of its probability distribution based on environmental predictors.

The coarse-scale distribution of Z. abelicea was predicted using MaxEnt, a maximum entropy-based machine learning program that estimates the probability distribution for a species' occurrence, based on the environmental constraints and its current occurrence data (Philips et al. 2006). The MaxEnt algorithm has been selected because it only requires present data for the study species, and it generally performs better than other modeling methods when working with small sample sizes (Pearson et al. 2007).

Records of the current position of Z. abelicea populations (15 points in total) were used as occurrence data for the model. For the selection of environmental predictors, the correlation of a broad set of environmental variables was measured by using a Pearson correlation coefficient. Environmental variables with a correlation coefficient of 0.7 or more were then excluded, resulting in a set of environmental variables (Table 1) which included topography, climate, land cover and soil characteristics.

The model was run, including all selected environmental variables (see Table 1 for details), using MaxEnt 3.3.3 through package dismo of the $\mathrm{R}$ statistical software (version 2.15.0; R Development Core Team, 2012). For evaluation purposes, the model was run following a fivefold evaluation procedure. For each run, the data set was split into $80 \%$ training and $20 \%$ test data, and the area under curve (AUC) of the receiver operating characteristic (ROC) was estimated for test data. AUC values range from 0 to 1 . Based on the literature, models with an AUC $\geq 0.7$ are generally considered acceptable, models with an AUC $\geq 0.8$ are considered excellent and models with an AUC $\geq 0.9$ are considered outstanding (Hosmer and Lemeshow 2000).

At a finer scale, within its distribution, the co-occurrence of Z. abelicea with other species has been studied across different spatial scales. In this regard, we attempted to reveal whether community structure follows a nested pattern, i.e., whether the species composition of small assemblages is a nested subset of the species composition of larger assemblages (sensu Ulrich et al. 2009). Nestedness was quantified with the nestedness metric based on overlap and decreasing fill (NODF). Compared to other metrics (summarized by Ulrich et al. 2009), NODF has been described as unrelated to matrix characteristics such as matrix size or shape (Almeida-Neto et al. 2008). The significance of the results was determined with a Monte Carlo procedure (500 iterations) employing R0 null model (Wright et al. 1998). R0 has been selected among other null models, as a more intermediate choice with respect to the type I-type II error trade-off (Morrison 2013).

Since nestedness may fail to reveal underlying processes causing the observed patterns, it has been suggested that additional methods, such as gradient analysis, are used in combination (Ulrich et al. 2009). A two-way indicator species analysis (TWINSPAN; Hill 1979) has thus been applied to achieve a further ordering of sites and species. Analysis was conducted at different spatial scales and more specifically at three different hierarchical levels: (1) patch level (2) line transect level and (3) site level. At the patch level, TWINSPAN was run for all 268 sampled patches, as well as for all subsets of patches belonging to each of the 23 line transects and to each of the 11 sites. For the line transect and the site levels, species presences were pooled at the respective level, and TWINSPAN was run on the resulting matrices $(23 \times 15$ and $11 \times 15$, respectively). Analysis was performed with the PC-ORD software (version 4.10; McCune and Mefford 1999).

Pairwise tests of species associations have been carried out using the method of Veech (2013). The probabilistic model of species co-occurrence allows to analytically (i.e., without randomization or simulation) obtain the probability that two selected species co-occur at a frequency either smaller or greater than the observed frequency of cooccurrence. The approach is not based on the use of a particular metric and randomization of the original data for the production of a $p$ value, but is both distribution-free and metric-free. This probabilistic model does not rely on any 
Table 1 Candidate variables for use in modeling of Z. abelicea distribution

\begin{tabular}{|c|c|}
\hline Variable & Name description \\
\hline \multicolumn{2}{|c|}{ Topographic variables } \\
\hline $\mathrm{alt}^{\mathrm{a}}$ & Altitude \\
\hline east $^{\mathrm{a}}$ & Slope eastness \\
\hline north $^{\mathrm{a}}$ & Slope northness \\
\hline slope $^{a}$ & Slope angle \\
\hline \multicolumn{2}{|c|}{ Climatic variables } \\
\hline rmean & Mean annual rainfall \\
\hline $\operatorname{rmax}^{\mathrm{a}}$ & Maximum monthly rainfall \\
\hline $\operatorname{rmin}^{\mathrm{a}}$ & Minimum monthly rainfall \\
\hline $\operatorname{tmean}^{\mathrm{a}}$ & Mean annual temperature \\
\hline $\operatorname{tmax}$ & Mean temperature of the hottest month \\
\hline $\operatorname{tmin}$ & Mean temperature of the coldest month \\
\hline \multicolumn{2}{|c|}{ Land cover variables } \\
\hline bare $^{\mathrm{a}}$ & Percent of pixel covered by bare soil \\
\hline herbs $^{\mathrm{a}}$ & Percent of pixel covered by herbaceous vegetation \\
\hline $\operatorname{trees}^{\mathrm{a}}$ & Percent of pixel covered by trees \\
\hline \multicolumn{2}{|c|}{ Soil variables } \\
\hline s.AWC & Available Water Storage Capacity \\
\hline s.IL ${ }^{\mathrm{a}}$ & Impermeable layer \\
\hline s.OR & Obstacles to roots \\
\hline s.SCC & Subsoil Calcium Carbonate \\
\hline s.SCECcl ${ }^{\mathrm{a}}$ & Subsoil cation exchange capacity for clay \\
\hline s.SCECs & Subsoil cation exchange capacity for soil \\
\hline s.SCLAY & Subsoil clay fraction \\
\hline s.SGRAV ${ }^{\mathrm{a}}$ & Subsoil gravel content \\
\hline s.SGYPS & Subsoil gypsum \\
\hline s.SOC ${ }^{\mathrm{a}}$ & Subsoil organic carbon \\
\hline s.SpH & Subsoil pH \\
\hline s.SSAL & Subsoil salinity \\
\hline s.SSAND & Subsoil sand fraction \\
\hline s.SSILT & Subsoil silt fraction \\
\hline s.SSOD ${ }^{\mathrm{a}}$ & Subsoil sodicity \\
\hline s.STEB ${ }^{\mathrm{a}}$ & Subsoil total exchangeable bases \\
\hline s.TCC & Topsoil Calcium Carbonate \\
\hline s.TCECcl & Topsoil cation exchange capacity for clay \\
\hline s.TCECs ${ }^{\mathrm{a}}$ & Topsoil cation exchange capacity \\
\hline s.TCLAY & Topsoil clay fraction \\
\hline s.TGRAV & Topsoil gravel content \\
\hline s.TGYPS & Topsoil gypsum \\
\hline s.TOC ${ }^{\mathrm{a}}$ & Topsoil organic carbon \\
\hline s.TpH & Topsoil pH \\
\hline s.TSAL & Topsoil salinity \\
\hline s.TSAND ${ }^{\mathrm{a}}$ & Topsoil sand fraction \\
\hline s.TSILT & Topsoil silt fraction \\
\hline s.TSOD ${ }^{\mathrm{a}}$ & Topsoil sodicity \\
\hline
\end{tabular}

Table 1 continued

\begin{tabular}{l}
\hline Variable Name description \\
\hline s.TTEB Topsoil total exchangeable bases \\
\hline Topographic variables were obtained from a Digital Elevation Model \\
(DEM) originally produced by NASA, freely available at the website \\
of the CGIAR cgiar-csi. Climatic variables were collected from the \\
Hellenic National Meteorological Service (HNMS) and the Water \\
Resource Department of the Prefecture of Crete (WRDPC). Land \\
cover variables as collected by MODerate resolution Imaging \\
Spectroradiometer (MODIS) sensor were downloaded from the Glo- \\
bal Land Cover Facility website (http://glcf.umd.edu). Soil variables \\
were retrieved from Harmonized World Soil Data Base (http:// \\
webarchive.iiasa.ac.at/Research/LUC/External-World-soil-database) \\
a Indicates that the variable was included in the model
\end{tabular}

data randomization; hence, it has a very low Type I error rate and is powerful since it also has a low Type II error rate. Nevertheless, taking into consideration the weakness of the probabilistic model in small data sets (Veech 2013), the classical chi-square method for species association has also been implemented.

\section{Results}

The probability distribution of Z. abelicea in the island of Crete, based on the model used, is presented in Fig. 2. This model seems to accurately represent existing conditions, as the points of occurrence of the species are in agreement with the areas of high probability of occurrence. This observation is also supported by the mean AUC results, which were 0.936 . Moreover, this model may indicate that the current distribution of $Z$. abelicea on the island of Crete is not only driven by the climate variables investigated in this study, as climatic variables have a percentage contribution of only $2.1 \%$, whereas the other factors contribute with $97.9 \%$ (Table 2).

Nestedness scores, calculated for different spatial scales, were significant $(p<0.05)$ for all hierarchical levels with the only exception of three lines at the patch level (LAS21, LAS2-2, NIA-2; Table 3). For all cases, NODF rowscores were higher than NODF column-scores, indicating that nestedness among species (i.e., species incidence) contributed more to the overall nestedness pattern than did nestedness among sites (i.e., species composition). This suggests that in the present case, differences in species associations are more important than differences in habitat variables of the sites in promoting nestedness. In other words, there are no sharp changes in species richness in a way that species assemblages in species-poor sites are 
Fig. 2 Predictive output of MaxEnt for the model. Darker areas represent areas of higher probability of occurrence of $Z$. abelicea. Current occurrence points are indicated with black dots with white outlines

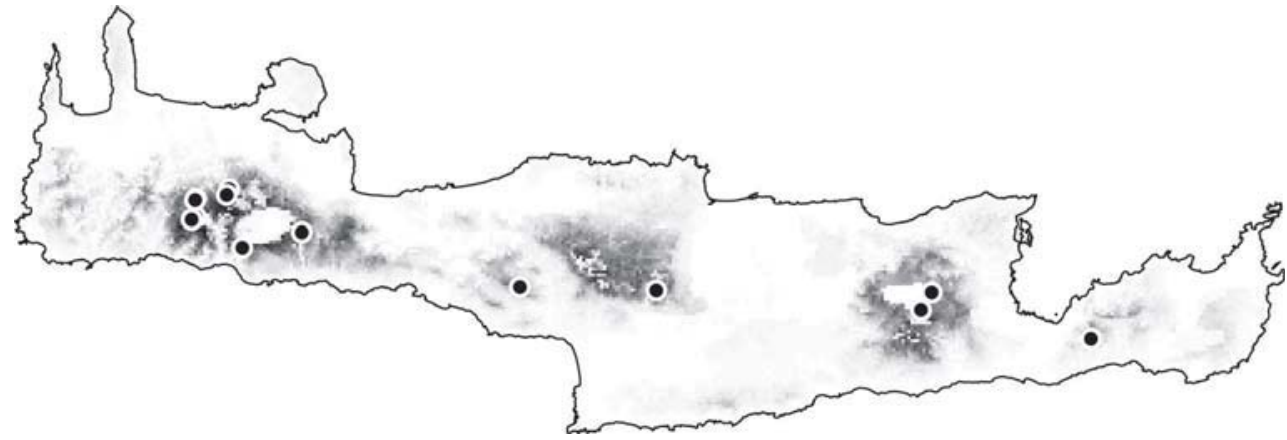

Table 2 Percent contribution of all variables used in the model, as estimated by MaxEnt

\begin{tabular}{ll}
\hline Variable & Percent contribution \\
\hline alt & $75(74.62)$ \\
east & $0(0.02)$ \\
north & $0(0.2)$ \\
slope & $1.6(0.92)$ \\
rmax & $0(0)$ \\
rmin & $0(0.38)$ \\
tmean & $2.1(1.96)$ \\
bare & $14.1(11.68)$ \\
herbs & $0(0)$ \\
trees & $0.1(1.3)$ \\
s.AWC & $0.1(0)$ \\
s.IL & $0(1.16)$ \\
s.SCECcl & $0.7(0.48)$ \\
s.SGRAV & $0.1(0.28)$ \\
s.SOC & $0(0.02)$ \\
s.SSOD & $4.7(4.38)$ \\
s.STEB & $1.3(1.12)$ \\
s.TCECs & $0(0.96)$ \\
s.TOC & $0(0.4)$ \\
s.TSAND & $0(0)$ \\
s.TSOD & $0.2(0.1)$ \\
\hline
\end{tabular}

Numbers in parentheses indicate the mean contribution of the model that resulted from the fivefold evaluation procedure

subsets of those from more species-rich sites, but the relatively more rare species occupy a subset of the sites at which more widespread species are found.

This statement becomes even more evident in the TWINSPAN results presented in Tables 4 and 5, where table arrangement simultaneously took place in rows and columns. Noteworthy, a gradient analysis through clustering has been used as a supplementary approach for the identification of driving forces that cause nested subsets.

The role of species associations has also been further explored with a pairwise species approach for the three dominant forest tree species, Z. abelicea, Acer sempervirens and Quercus coccifera L. Both the probabilistic and classical chi square approaches yielded identical results (Table 6). The non-significant relationship was the dominant pattern at the patch level in the two hierarchical scales, with only a few local exceptions of negative associations in the case of $Z$. abelicea and A. sempervirens. Nevertheless, by incorporating all patches at the island level in one data matrix, negative association was revealed for the pairs $Z$. abelicea-A. sempervirens and Z. abelicea-Q. coccifera, whereas positive association became apparent for the pair A. sempervirens $-Q$. coccifera.

Results on seedlings and the mode of reproduction of Z. abelicea plants in sampling sites are presented in Online Resource 1. No seedlings were recorded in the line transects under investigation and the dominant way of reproduction at the sites was vegetative through sprouting. In the Omalos area, A. sempervirens seedlings measured under $Z$. abelicea shrubs/bushes and out of Z. abelicea canopies revealed statistically significant differences (chi-square test, $p<0.05)$.

As compared to the historical records, the recent distribution of Z. abelicea (1993-2010) matches almost exactly the historical occurrences, and no dramatic shifts in distribution could be demonstrated for the past 300 years. However, several isolated populations, mainly in Lefka Ori and Psiloritis, appear to have gone extinct during the second half of the twentieth century (Kozlowski et al. 2013), and new populations could not be discovered during recent field investigations.

At the finer scale (patch level), Z. abelicea had a relative frequency of $73.51 \%$, which was unequally distributed in the different categories, with tree categories (intermediateM2 and large trees-L) presenting the lowest values.

Furthermore, several patterns of relationships between patch size and other parameters become evident; one such is the absence of any correlation between the sizes of patches and the number of species comprised in it (Fig. 3). Moreover, a statistically significant negative correlation was found between the abundance of each Z abelicea shrub form and the logarithm of the patch size $\left(R^{2}=0.6568,0.4911\right.$ and 0.5743 for small, intermediate 
Table 3 Results of nestedness tests based on the R0 null model

\begin{tabular}{|c|c|c|c|c|}
\hline Data set & Fill & NODFcolumns & NODFrows & NODF \\
\hline All patches & 0.151 & $28.03(+)$ & $47.52(+)$ & $47.46(+)$ \\
\hline All lines & 0.371 & $56.74(+)$ & $70.15(+)$ & $66.22(+)$ \\
\hline All sites & 0.412 & $55.94(+)$ & $64.97(+)$ & $59.05(+)$ \\
\hline LAS1_1 & 0.173 & $5.24(-)$ & $57.04(+)$ & $20.78(+)$ \\
\hline LAS1_2 & 0.213 & $11.31(-)$ & $65.56(+)$ & $27.58(+)$ \\
\hline LAS1_3 & 0.233 & $5.08(-)$ & $35.56(+)$ & $8.89(-)$ \\
\hline LAS2_1 & 0.164 & $5.52(-)$ & $40.61(+)$ & 17.58 \\
\hline LAS2_2 & 0.225 & $10.48(-)$ & $77.68(+)$ & 24.62 \\
\hline LAS3_1 & 0.161 & $3.54(-)$ & $65.15(+)$ & $27.32(+)$ \\
\hline LAS3_2 & 0.2 & 10.24 & $68.89(+)$ & $17.57(+)$ \\
\hline NIA_1 & 0.11 & 2.86 & $32.97(+)$ & $16.84(+)$ \\
\hline NIA_2 & 0.21 & $8.41(-)$ & $69.84(+)$ & 18.65 \\
\hline OMA1_1 & 0.113 & 4.83 & $42.22(+)$ & $16.04(+)$ \\
\hline OMA1_2 & 0.072 & 0.48 & $7.69(+)$ & $3.55(+)$ \\
\hline OMA2_1 & 0.089 & 1.43 & $43.94(+)$ & $17.84(+)$ \\
\hline OMA2_2 & 0.125 & 1.95 & $60.71(+)$ & $14.32(+)$ \\
\hline OMA3_1 & 0.129 & 10.55 & $48.02(+)$ & $29.28(+)$ \\
\hline OMA3_2 & 0.171 & $10.45(-)$ & $68.96(+)$ & $37.61(+)$ \\
\hline OMA4_1 & 0.147 & 11.35 & $51.43(+)$ & $31.39(+)$ \\
\hline OMA4_2 & 0.118 & 4.56 & $25(+)$ & $13.27(+)$ \\
\hline PSI_1 & 0.171 & 12.97 & $59.43(+)$ & $34.54(+)$ \\
\hline PSI_2 & 0.152 & $9.15(-)$ & $63.37(+)$ & $34.32(+)$ \\
\hline STA_1 & 0.174 & 12.22 & $69.23(+)$ & $36.52(+)$ \\
\hline STA_2 & 0.19 & $5.9(-)$ & $59.62(+)$ & $28.8(+)$ \\
\hline AMB_1 & 0.107 & $1.71(-)$ & $53.33(+)$ & $27.52(+)$ \\
\hline AMB_2 & 0.164 & $6.98(-)$ & $69.21(+)$ & $38.1(+)$ \\
\hline AMB & 0.136 & $5.77(-)$ & $63.03(+)$ & $51.89(+)$ \\
\hline LAS1 & 0.203 & $10.46(-)$ & $47.59(+)$ & $38.52(+)$ \\
\hline LAS2 & 0.189 & $9(-)$ & $58.04(+)$ & $39.38(+)$ \\
\hline LAS3 & 0.174 & $8.85(-)$ & $58.82(+)$ & $38.48(+)$ \\
\hline NIA & 0.143 & $8.81(-)$ & $44.84(+)$ & $32.83(+)$ \\
\hline OMA1 & 0.09 & 3.07 & $24.11(+)$ & $17.94(+)$ \\
\hline OMA2 & 0.103 & $1.79(-)$ & $49.47(+)$ & $32.5(+)$ \\
\hline OMA3 & 0.149 & $12.49(-)$ & $57.41(+)$ & $48.18(+)$ \\
\hline OMA4 & 0.133 & 10.3 & $37.57(+)$ & $31.64(+)$ \\
\hline PSI & 0.162 & $13.43(-)$ & $60.07(+)$ & $49.93(+)$ \\
\hline STA & 0.182 & $10.86(-)$ & $59.74(+)$ & $47.81(+)$ \\
\hline
\end{tabular}

$(+)$ Observed NODF is statistically significantly higher than that expected by chance (high nestedness)

(-) Observed NODF is statistically significantly lower than that expected by chance (low nestedness)

"All patches" row refers to a matrix created by all 268 patch data, "all lines" refers to pooled presence data for the 23 line transects and "all sites" refers to pooled presence data for the 11 sites. Individual site matrices are coded based on population (see Table S1), while individual line transect matrices are coded in the format S_L, where S is the site code and $\mathrm{L}$ the index of the line transect. "Fill" refers to the total fit of the matrix. Columns "NODFcolumns" and "NODFrows" refer to the NODF as measured only according to matrix columns and rows, respectively, while "NODF" refers to the total NODF and large shrub forms respectively; $p<0.01$ in all cases) (Fig. 4a-c). Such a trend was not maintained in the tree forms (Fig. 4d), where no correlation was found.

As far as the co-occurrence of Z. abelicea with other species is concerned at the patch level, increasing numbers of species co-occurring with $Z$. abelicea resulted in a decrease of the number of patches where co-occurrence is recorded (Fig. 5a).

The same trend appears when correlating the number of cooccurring species with the abundance of $Z$. abelicea per patch (Fig. 5b). The deviation in the case of 5 species is presumably reflective of the low number of available patches.

When exploring the co-occurrence of $Z$. abelicea categories in patches, it also becomes obvious that many patches (171) with shrub category occurrences (small, intermediate and large shrubs) will be void of intermediate and large trees. We only identify three patches where the intermediate and the large trees co-occur or occur in the absence of shrubs. A chi-square test of the contingency table of Zelkova shrubs and trees showed a statistically significant deviation from the expected by chance frequencies. Specifically, intermediate and large trees were found less frequently than expected.

\section{Discussion}

In the case of the extant Mediterranean flora, many ancient taxa evolved during the Cenozoic, well before the typical Mediterranean climate regime was established (Pulido et al. 2008). A number of Tertiary relict taxa evolved from lineages that thrived under warm temperate (fully humid or winter dry) climates during most parts of the Cenozoic. Examples of Tertiary relict taxa that are at present confined to the Mediterranean region are, among others, Platanus orientalis L., Liquidambar orientalis Mill., Z. abelicea and $Z$. sicula. In contrast to the Cenozoic climate, today, these taxa have to cope with summer dry and hot conditions typical of the Mediterranean climate. As a result, these climate relict trees invariably exhibit highly fragmented ranges and low population sizes in southern Europe (Pulido et al. 2008). Zelkova abelicea is such a relict species, persisting in a few sites in the island of Crete.

Probability of occurrence and biotic interactions

In this study, the low explanatory contribution of the climatic variables in the model indicates that the current distribution of $Z$. abelicea on the island of Crete may not be driven by climate alone, but that other factors may play a central role. Of course, we are well aware that the model is strongly depending on the choice of climatic 
Table 4 Results of the two-way indicator species analysis on the line matrix (each column represents a line transect)

\begin{tabular}{|c|c|c|c|c|c|c|c|c|c|c|c|c|c|c|c|c|c|c|c|c|c|c|c|}
\hline & OMA1_1 & OMA3_1 & ОМАз_2 & OMA4_1 & OMA4_2 & LAS1_2 & PSI_1 & LAS1_1 & LAS1_3 & LAS2_1 & LAS2_2 & LAS3_1 & LAS3_2 & NIA_ 1 & OMA1_2 & PSI_2 & STA_1 & STA_2 & OMA2__1 & OMA2_2 & AMB_1 & AMB_2 & $\mathrm{NIA}_{-}{ }_{2}$ \\
\hline CraMon & 1 & - & - & 1 & - & - & - & - & - & - & - & - & - & - & - & - & - & - & - & - & - & - & - \\
\hline RhaOle & - & 1 & 1 & 1 & 1 & - & - & - & - & - & - & - & - & - & - & - & - & - & - & - & - & - & - \\
\hline RhaAla & - & 1 & - & 1 & 1 & 1 & 1 & - & - & - & - & - & - & - & - & - & - & - & - & - & - & - & - \\
\hline QueCoc & 1 & 1 & 1 & 1 & 1 & 1 & 1 & 1 & 1 & 1 & 1 & - & 1 & 1 & 1 & 1 & - & - & - & - & - & - & - \\
\hline ZelAbe & 1 & 1 & 1 & 1 & 1 & 1 & 1 & 1 & 1 & 1 & 1 & 1 & 1 & 1 & 1 & 1 & 1 & 1 & 1 & 1 & 1 & 1 & 1 \\
\hline EupAca & - & 1 & 1 & 1 & 1 & 1 & 1 & 1 & 1 & 1 & 1 & 1 & 1 & 1 & - & 1 & 1 & 1 & - & - & 1 & 1 & 1 \\
\hline BerCre & 1 & 1 & 1 & 1 & 1 & 1 & 1 & 1 & 1 & 1 & 1 & - & - & 1 & - & 1 & 1 & 1 & 1 & 1 & 1 & 1 & 1 \\
\hline AceSem & 1 & 1 & 1 & 1 & 1 & 1 & 1 & 1 & 1 & 1 & 1 & 1 & 1 & 1 & 1 & 1 & 1 & - & 1 & 1 & 1 & 1 & 1 \\
\hline Dapser & - & - & - & - & - & - & - & - & - & - & - & - & - & - & - & - & 1 & 1 & - & - & - & - & - \\
\hline SarSpi & - & - & - & - & - & - & - & - & - & - & - & - & - & - & - & - & 1 & - & - & - & - & - & - \\
\hline Teu & - & - & - & - & - & - & - & - & - & - & - & - & 1 & - & - & - & - & - & - & - & - & - & - \\
\hline PhlCre & - & - & - & - & - & 1 & 1 & - & 1 & 1 & 1 & 1 & 1 & - & - & 1 & 1 & 1 & - & - & - & - & - \\
\hline PhlLan & - & - & - & - & - & - & - & - & - & - & - & - & - & - & - & - & - & - & - & - & - & 1 & - \\
\hline VerSpi & - & - & - & - & - & - & - & - & - & - & - & - & - & - & - & - & - & - & - & - & - & - & 1 \\
\hline PruPro & - & - & - & - & - & - & - & - & - & - & - & - & - & 1 & - & - & - & - & - & - & - & - & 1 \\
\hline
\end{tabular}

Value 1 indicates presence of the according species to that particular line transect, while horizontal dashes (-) indicate absence. Double lines delimit the groups that resulted from the first division and single lines delimit the groups that resulted from the second one

Species abbreviations:AceSem Acer sempervirens, BerCre Berberis cretica, CraMon Crataegus monogyna, DapSer Daphne sericea, EupAca Euphorbia acanthothamnos, PhlCre Phlomis cretica, PhlLan Phlomis lanata, PruPro Prunus prostrata, QueCoc Quercus coccifera, RhaAla Rhamnus alaternus, RhaOle Rhamnus oleoides, SarSpi Sarcopoterium spinosum, Teu Teucrium sp, VerSpi Verbascum spinosum, ZelAbe Zelkova abelicea

Table 5 Results of the two-way indicator species analysis on the line matrix (each column represents a site)

\begin{tabular}{|c|c|c|c|c|c|c|c|c|c|c|c|}
\hline & NIA & OMA1 & OMA3 & OMA4 & LAS1 & PSI & LAS2 & LAS3 & AMB1 & OMA2 & STA \\
\hline PruPro & 1 & - & - & - & - & - & - & - & - & - & - \\
\hline VerSpi & 1 & - & - & - & - & - & - & - & - & - & - \\
\hline RhaAla & - & - & 1 & 1 & 1 & 1 & - & - & - & - & - \\
\hline RhaOle & - & - & 1 & 1 & - & - & - & - & - & - & - \\
\hline CraMon & - & 1 & - & 1 & - & - & - & - & - & - & - \\
\hline QueCoc & 1 & 1 & 1 & 1 & 1 & 1 & 1 & 1 & - & - & - \\
\hline AceSem & 1 & 1 & 1 & 1 & 1 & 1 & 1 & 1 & 1 & 1 & 1 \\
\hline BerCre & 1 & 1 & 1 & 1 & 1 & 1 & 1 & - & 1 & 1 & 1 \\
\hline EupAca & 1 & - & 1 & 1 & 1 & 1 & 1 & 1 & 1 & - & 1 \\
\hline ZelAbe & 1 & 1 & 1 & 1 & 1 & 1 & 1 & 1 & 1 & 1 & 1 \\
\hline PhlCre & - & - & - & - & 1 & 1 & 1 & 1 & - & - & 1 \\
\hline Teu & - & - & - & - & - & - & - & 1 & - & - & - \\
\hline SarSpi & - & - & - & - & - & - & - & - & - & - & 1 \\
\hline DapSer & - & - & - & - & - & - & - & - & - & - & 1 \\
\hline
\end{tabular}

Value 1 indicates presence of the according species to that particular line transect, while horizontal dashes (-) indicate absence. Double lines delimit the groups that resulted from the first division and single lines delimit the groups that resulted from the second one. Species abbreviations as in Table 4

variables, but a minimum set of available parameters have been chosen to avoid overfitting, which in turn may result in artifacts (Beaumont et al. 2005; Heikkinen et al. 2006; Araújo and Peterson 2012). The fact that the total contribution of the direct abiotic variables (i.e., soil, landscape and climate variables) in the model reaches $10.8 \%$, whereas bare soil and plant cover attain 14.1 and $0.1 \%$, respectively, also indicates that patterns resulting from disturbance and biotic interactions may also be important. Besides, altitude, which is the highest contributing variable in the model $(75 \%)$, as an indirect variable may also comprise biotic interactions and partially may reflect nonselected climatic variables.
These results depict a scenario partially different as referred to the closest biogeographical and ecological relative Z. sicula, particularly with concern to the role of certain abiotic factors such as available water storage capacity in the soil. Actually, the current distribution of the Sicilian species is suggested to be strictly depending on underground water resources, since both known populations are essentially restricted to the bottom of thalwegs (Garfî et al. 2011). This situation has been interpreted as an adaptive strategy or a refugial persistence allowing the species to face the constraints of summer water stress typical of Mediterranean climate. According to that, besides palaeoecological data (cf. Béguinot 1929; Follieri 
Table 6 Results of the pairwise association tests using chi-squared tests and the probabilistic method of Veech (2013)

\begin{tabular}{|c|c|c|c|c|c|c|}
\hline & \multicolumn{3}{|c|}{ chi squared } & \multicolumn{3}{|c|}{ Probabilistic } \\
\hline & Z-A & Z-Q & A-Q & Z-A & Z-Q & A-Q \\
\hline All patches & - & - & + & - & - & + \\
\hline LAS1_1 & 0 & 0 & 0 & 0 & 0 & 0 \\
\hline LAS1_2 & 0 & 0 & 0 & 0 & 0 & 0 \\
\hline LAS1_3 & 0 & 0 & 0 & 0 & 0 & 0 \\
\hline LAS2_1 & 0 & 0 & 0 & 0 & 0 & 0 \\
\hline LAS2_2 & 0 & 0 & 0 & 0 & 0 & 0 \\
\hline LAS3_1 & 0 & 0 & 0 & 0 & 0 & 0 \\
\hline LAS3_2 & 0 & 0 & 0 & 0 & 0 & 0 \\
\hline NIA_1 & 0 & 0 & 0 & 0 & 0 & 0 \\
\hline NIA_2 & 0 & 0 & 0 & 0 & 0 & 0 \\
\hline OMA1_1 & 0 & 0 & 0 & 0 & 0 & 0 \\
\hline OMA1_2 & - & 0 & 0 & - & 0 & 0 \\
\hline OMA2_1 & 0 & 0 & 0 & 0 & 0 & 0 \\
\hline OMA2_2 & 0 & 0 & 0 & 0 & 0 & 0 \\
\hline OMA3_1 & 0 & 0 & 0 & 0 & 0 & 0 \\
\hline OMA3_2 & 0 & 0 & 0 & 0 & 0 & 0 \\
\hline OMA4_1 & 0 & 0 & 0 & 0 & 0 & 0 \\
\hline OMA4_2 & 0 & 0 & 0 & 0 & 0 & 0 \\
\hline PSI_1 & 0 & 0 & 0 & 0 & 0 & 0 \\
\hline PSI_2 & 0 & 0 & 0 & 0 & 0 & 0 \\
\hline STA_1 & 0 & 0 & 0 & 0 & 0 & 0 \\
\hline STA_2 & 0 & 0 & 0 & 0 & 0 & 0 \\
\hline AMB_1 & 0 & 0 & 0 & 0 & 0 & 0 \\
\hline AMB_2 & 0 & 0 & 0 & 0 & 0 & 0 \\
\hline LAS1 & 0 & 0 & 0 & 0 & 0 & 0 \\
\hline LAS2 & 0 & 0 & 0 & 0 & 0 & 0 \\
\hline LAS3 & - & 0 & 0 & - & 0 & 0 \\
\hline NIA & 0 & 0 & 0 & 0 & 0 & 0 \\
\hline OMA1 & - & 0 & 0 & - & 0 & 0 \\
\hline OMA2 & - & 0 & 0 & - & 0 & 0 \\
\hline OMA3 & 0 & 0 & 0 & 0 & 0 & 0 \\
\hline OMA4 & 0 & 0 & 0 & 0 & 0 & 0 \\
\hline PSI & - & 0 & 0 & - & 0 & 0 \\
\hline STA & 0 & 0 & 0 & 0 & 0 & 0 \\
\hline AMB & 0 & 0 & 0 & 0 & 0 & 0 \\
\hline
\end{tabular}

In columns, pairs of the three species Z. abelicea, A. sempervirens and $Q$. coccifera are denoted by pairs of the letters $\mathrm{Z}, \mathrm{A}$ and $\mathrm{Q}$, respectively. Matrix codes are the same as in Table 3

0 No statistically significant association detected

+ Statistically significant positive association detected ( $p$ value $<$ 0.05)

- Statistically significant negative association detected ( $p$ value $<$ 0.05

et al. 1986; De Paola et al. 1997) and observations on exceptional performances of a few cultivated trees (Garfî, unpublished), a more humid environment as is found at

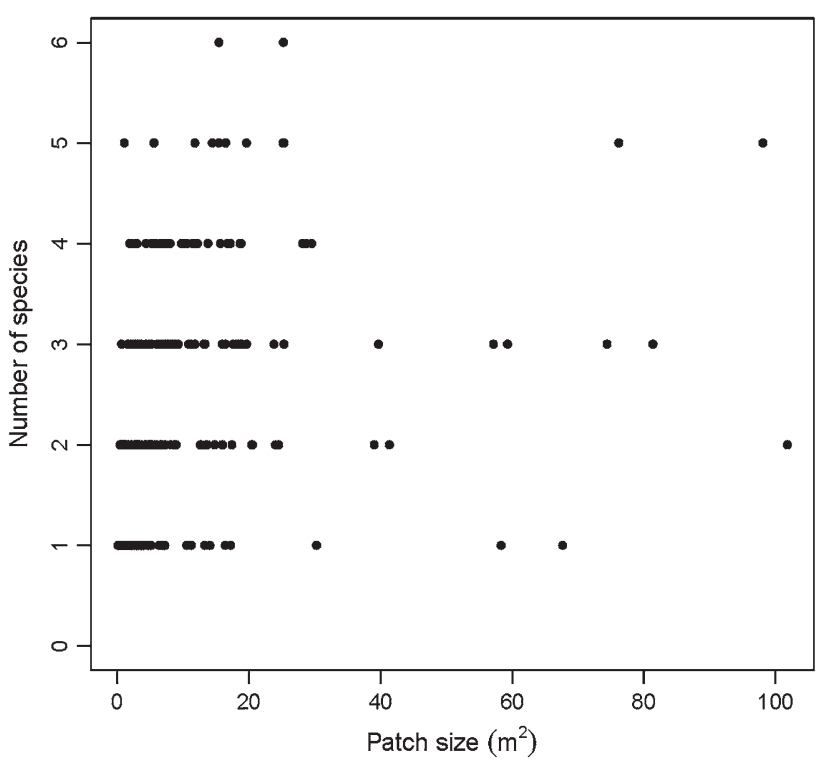

Fig. 3 Patch size in square meters and the number of species comprised in it. Each point represents a single patch out of the 268 sampled

higher elevation (e.g., supra-Mediterranean or montane forest habitats dominated by Fagus, Acer, Carpinus, Taxus, deciduous-type Quercus, etc.) is inferred to better match with the ecological requirements of Z. sicula (Garfî and Buord 2012). Such an assumption could be somehow consistent with the main results of distribution modeling of Z. abelicea, showing the overwhelming significance of altitude in affecting the species persistence.

Even though biotic interactions have generally been considered to be unimportant in determining large-scale distributions (for a review see Wisz et al. 2013), they have recently been suggested to affect species distributions and plant assemblages at regional, continental and global scales (Hampe and Jump 2011; Wisz et al. 2013). Thus, biotic interactions ought to be considered in management practices of Z. abelicea.

The possible role of biotic interactions is also supported by the fact that nestedness among species contributed more to the overall nestedness pattern than did nestedness among sites. According to Ulrich et al. (2009), nestedness is a pattern of species co-occurrence, intrinsically related to the degree of species aggregation, and the correlation between nestedness and co-occurrence metrics might be used to identify non-random species associations.

At the line and at the site level, the results of the TWINSPAN approach strengthen the above findings, revealing that $A$. sempervirens and $Z$. abelicea are widespread in all lines and sites, along which species loss and species replacements take place among the remaining species. However, a divergence from this pattern is observed at the patch level, where the two species seem to 

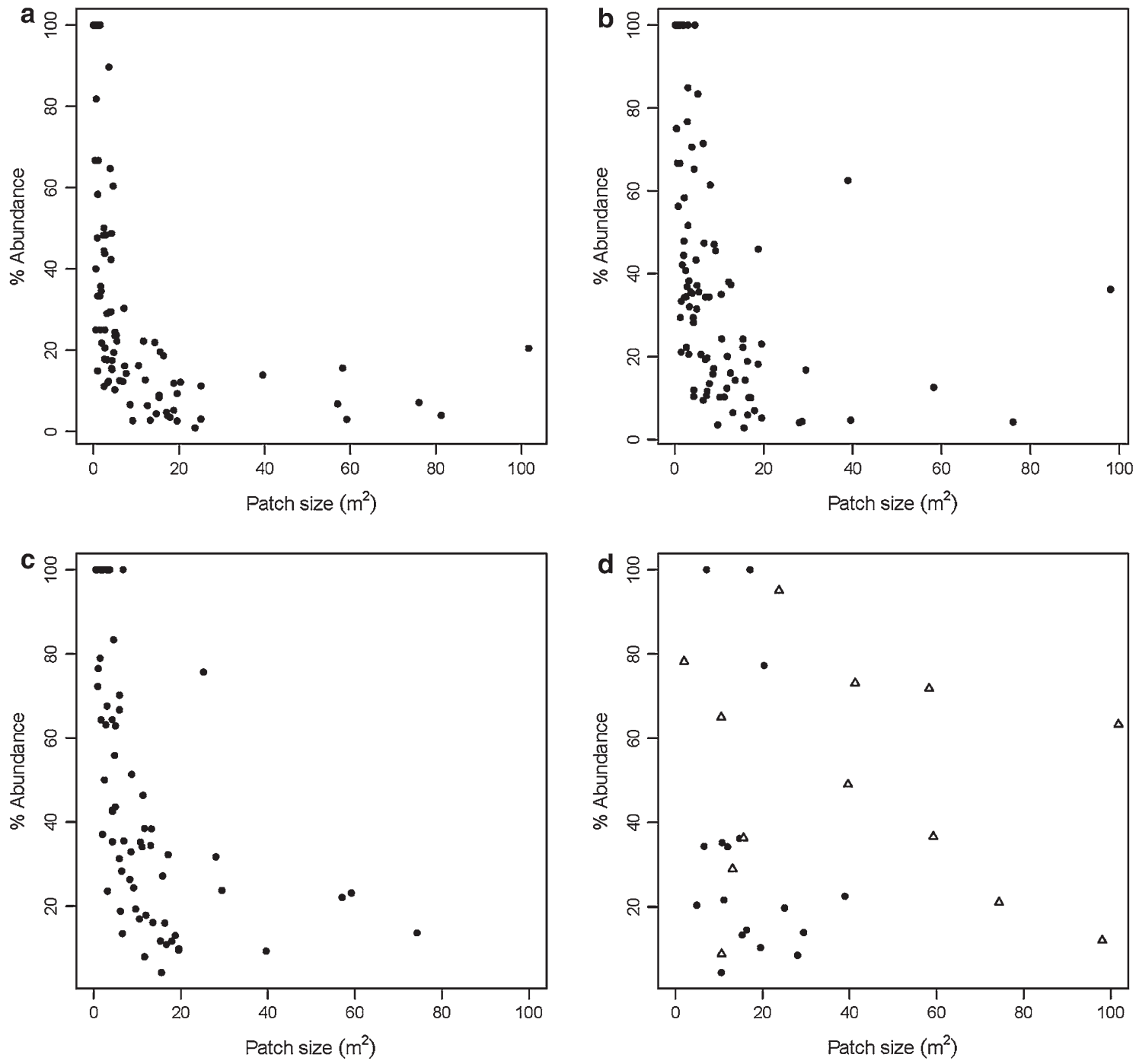

Fig. 4 Relationship between patch size in square meters and percent relative abundance of each Z. abelicea form: S1 (a), S2 (b), M1 (c), M2 (d, black dots) and L (d, white triangles). Codes are in accordance with "Materials and methods"

Fig. 5 Frequency of the number of species co-occurring with Z. abelicea in each patch (a) and its relationship with the patch abundance of Z. abelicea (b). In (b), boxes are 0.25 and 0.75 quantiles and medians, while whiskers are 1.5-fold interquantile range

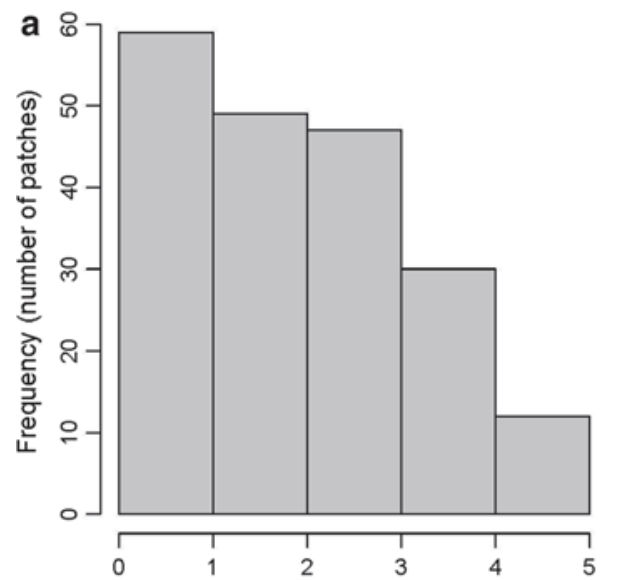

Number of species co-occurring with $Z$. abelicea

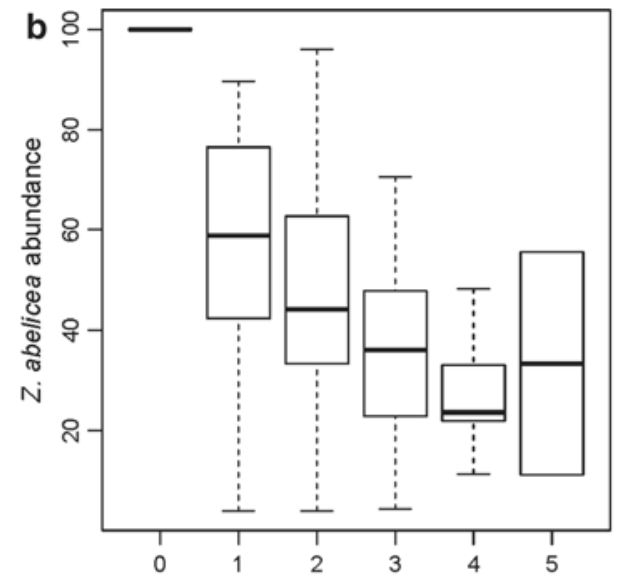

Number of species co-occurring with $Z$. abelicea 
be distributed independently, as also supported by the nonsignificance of the pairwise species association metrics.

Although this may seem contradictory at first, it may be related to different driving forces, which determine patterns at the different hierarchical levels. For example, $Z$. abelicea and $A$. sempervirens may exhibit positive interactions at the site and line levels, which diminish at the patch level. This is in line with their co-occurrence according to nestedness and TWINSPAN results at these levels and is consistent with the differentiated pattern at the patch level.

By positive interaction, we mean a situation where the presence of one species modifies the environment in ways that reduce some physical disturbance or stress, so that less tolerant species perform better. Facilitation is the most frequent plant-plant interaction in stressful environments (Bertness and Callaway 1994; Callaway et al. 2002; Gómez-Aparicio et al. 2004), where facilitator species can improve conditions to the benefit of other species.

In our case, a possible positive interaction between $Z$. abelicea and $A$. sempervirens could be related to the hydraulic redistribution of water in the soil (Brooksbank et al. 2011), a process which describes transport of water via roots along water potential gradients from wetter to drier parts of the soil profile. This usually occurs nocturnally, when reduced transpiration results in the root water potential in dry soil layers rising above the water potential of the surrounding soil.

Hydraulic redistribution has been shown to add in some cases the equivalent of $0.7 \mathrm{~mm} \mathrm{day}^{-1}$ of water to the upper $1 \mathrm{~m}$ of soil (Scholz et al. 2010), and the phenomenon has been largely investigated for Acer saccharum (Stoll and Weiner 2001). During drought periods, Acer saccharum demonstrates "hydraulic lift," a nocturnal uptake of water by roots from deep soil layers that is released from shallow roots into upper soil layers (Dawson 1993), so that neighboring plants can use 3-60\% of the hydraulically lifted water supplied by Acer saccharum trees. Overall, hydraulically redistributed water has been shown to increase annual water use in A. saccharum forest by 19-40\% (Caldwell et al. 1998).

Consistently, although no specific measurements have been carried out in this study, we hypothesize that in such a positive interaction between $Z$. abelicea and A. sempervirens, Acer possibly contributes to the hydraulic redistribution, through "hydraulic lift." Our assumption is in agreement with Valiente-Banuet et al. (2006) who reported that a large number of Tertiary relict species in Mediterranean climate ecosystems appear to have been preserved by the facilitative effects of other species. Nevertheless, whether A. sempervirens is a modern Quaternary plant lineage is not clear. Although an adaptive shift of A. sempervirens to the Mediterranean climate, accompanied with increased mutational activities, could have occurred in the Pleistocene (Grimm et al. 2007), the "Quaternary species hypothesis" is still controversial for A. sempervirens. Our assumption also suggests that Z. $a$ belicea would belong to the category of biotically sustained (BS) relicts (Hampe and Jump 2011), i.e., species that requires for its persistence a mutualist that is also limited by climate.

Along this line of thoughts, any conservation practice addressed to the removal of $A$. sempervirens trees from the ecosystem in benefit of Z. abelicea should carefully consider the dependence of the latter on the presence of the first. Further research is clearly and critically needed to explore these plant-plant interactions over all ranges of species co-occurrence, as the initial facilitation between species can shift into competition at a certain ontogenetic stage (Valladares 2008). This ontogenetic shift may help to reconcile contrasting results on facilitation versus competition outcomes on plant-plant interaction in dry ecosystems.

Additional positive interactions, such as the nursing role of $Z$. abelicea to the establishment of A. sempervirens seedlings, cannot be excluded. According to our field observations, significantly more A. sempervirens seedlings are found under $Z$. abelicea shrubs than in open areas or under other species. This nursing behavior could be related to the protection of A. sempervirens seedling from grazing, high radiation, wind, low temperatures and/or to the preservation of soil water and nutrients. This observation is in agreement with other studies where Acer saplings have been demonstrated to need the protection of nurse species (Gómez-Aparicio et al. 2005; Quero et al. 2008). Species such as Sorbus or Quercus spp. have been observed to establish better under shrub canopies as well, owing to the lacking ability of seedlings and saplings to withstand high radiation (Mendoza et al. 2009) or to the shelter role played by shrubs against animal browsing (Di Pasquale and Garfi 1998). Nevertheless, in order to support such a hypothesis about a possible nursing role of $Z$. abelicea, more research, measurements and experiments will be needed.

On the other hand, the lower frequency of co-occurrence between $Z$. abelicea and $Q$. coccifera prompts different assumptions. Although the relationship between $Z$. abelicea and $Q$. coccifera is unknown at the moment, it may possibly be linked to the lower tolerance of $Z$. abelicea to dryness and disturbance, as compared to $Q$. coccifera. The latter is generally well known for its high degree of physiological and morphological plasticity (Valladares et al. 2002). This hypothesis is also in support of the assumption of the supposed dependence of Z. abelicea on the "hydraulic lift." Moreover, the distribution of $Q$. coccifera is mostly limited to the dry, higher parts of dolines in the present case and further supports this hypothesis. 


\section{Disturbance and population structure}

Focusing on the patches, the absence of correlation between the size of a patch and the number of species it contains seems analogous to the observations recorded by Gavilán et al. (2002) in Spain. The question arising here is whether disturbance, especially grazing, could be invoked in the explanatory framework of the absence of correlation. The participation of bare soil as an explanatory variable in the full model with a contribution of $14.1 \%$ seems to be in strong support of such an assumption.

In fact, disturbance has been demonstrated to influence species richness (Mackey and Currie 2001), and several hypotheses have been proposed for the diversity-disturbance relationship. The intermediate disturbance hypothesis (IDH) (Levin and Paine 1974; Connell 1978) can be seen as the leading hypothesis for this relationship, whereas empirical evidences reviewed in Proulx and Mazumder (1998) suggest that this relationship would depend on the productivity of the ecosystem. IDH predicts small and large species numbers at low or high/intermediate levels of disturbance, respectively, and this independently of patch size.

Additionally, in case the dominant species is the one mainly affected by disturbance pressure both in large and small patches, the number of participating species in the patches is increasing. Yet, when the dominant species escapes disturbance or, on the contrary, disappears from the area due to disturbance pressure, the pressure is redirected to the non-dominant species. The number of participating species in the patches will thus be decreasing, leading to a small number of species independent of the patch size. In any case, diversity-disturbance relationship in both patch sizes can be either negative or positive depending on the intensity of disturbance as well as on the productivity of ecosystem, leading to a small or a large number of species.

As an outcome of the above, it can be assumed that the absence of correlation between species number and patch size, incorporating all the patches of the sites investigated in this study, may be related to multiple disturbance, especially grazing aspects (in terms of frequency and intensity) and their interactions, which usually cause mosaic disturbance patterns.

Consequently, as the persistence of $Z$. abelicea does not only seem to be a matter of isolated enclaves in suitable climatic areas, other disturbances and more specifically herbivory should be considered as a prominent factor influencing the response of Z. abelicea. Herbivory should therefore be considered in conservation planning as well, mainly by promoting controlled grazing as a management tool in some selected cases rather than favoring their complete removal by fencing. Generally, morphological and reproductive plasticity could possibly represent an advantageous strategy to track changing conditions due to disturbance, in particular mosaic disturbance (Valladares and Gianoli 2007; Keppel et al. 2012) which characterizes Mediterranean refugia, and further facilitate resistance to climate change in highly variable environments (Richter et al. 2012). Noteworthy in this context, fencing of the Psiloritis population (Rouvas forest) has proven unsuccessful as heavy snow has partially destroyed the fences, and as local shepherds do not prevent their animals from entering fenced areas.

Nevertheless, despite the absence of the above correlation between patch size and number of species occurring per patch, Z. abelicea abundance per patch seems to be decreasing as the number of other species per patch increases (Fig. 5b). This finding could partially be explained by the fact that $A$. sempervirens is the dominant and widespread tree species in the selected sites and, as a consequence, a reduction in its abundance due to grazing and/or browsing would lead to the increase in the number of other co-occurring species per patch. This is not, however, the case of $Z$. abelicea abundance per patch, which in contrary to the other woody species is negatively influenced by the reduction in $A$. sempervirens. In addition, this finding might also be reflective or indicative of a weak competitive ability of Z. abelicea against other woody species.

Still regarding patch size, the inverse correlation between the abundance of $Z$. abelicea shrubs and patch size is in opposition to a pattern where high and low abundances of tree habits can indifferently be observed in both small and large patches. Fazan et al. (2012), demonstrated that severely browsed $Z$. abelicea trees, while often remaining very small, can attain high ages (>500 years) and thereby greatly surpass in age large, normally growing neighboring trees. It can thus be suggested that the different populations do not represent different successional stages, with shrubs at the first and trees at the following stages. Rather, tree habit seems to be the result of escape from grazing and independent of succession. This concept is further supported by the fact $Z$. abelicea trees do not seem to form continuous and exclusive forests at the studied sites, but that they occur in mixed forests with $A$. sempervirens and Q. coccifera (Egli 1997; Søndergaard and Egli 2006). Additionally, paleobotanical evidence showed the co-occurrence of Zelkova species with evergreen oaks and other species (Follieri et al. 1986, 1989; Boyd 2009). Therefore, any restoration efforts for Z. $a$ belicea (e.g., reforestation for the formation of single species stands) should take this aspect into account (see also Godefroid et al. 2011; Loss et al. 2011).

By taking into consideration coarse- and fine-scale results, a matter of scale appears (Levin 1992) and an additional question arises-whether the persistence of 
Z. abelicea is the result of bottom-up processes, where processes at a lower hierarchical level determine the dynamics at a higher level (Jeltsch et al. 2008) or the result of top-down processes. In other words, the issue is whether the current distribution of spatially structured Z. abelicea populations in Crete is defined by ecological processes taking place at the patch level (bottom-up) or if persistence at the patch level is defined by ecological processes at the broader area level (top-down).

In a metapopulation context, despite the reduction in relative frequency at the patch level, persistence is possible if re-colonization exceeds extinction (Hanski 1991). However, in the investigated patches, young seedlings could not be recorded and vegetative propagation was the only visible way of reproduction for the shrubby plants of $Z$. abelicea, which exhibit extremely higher frequencies compared to the tree forms. Interactions between populations clearly are an essential prerequisite of metapopulation processes, but such a structure does not seem to be present in the case of $Z$. abelicea.

Nevertheless, we cannot exclude interactions between some of the Z. abelicea populations in Lefka Ori, where fruiting, though limited, was observed in Z. abelicea large trees (Fazan et al. 2012), but the absence of Z. abelicea young seedlings, even in these populations, clearly diminishes the likelihood of such occurrences. Thus, the population structure of Z. abelicea seems to follow the "regional ensembles" pattern, in which local processes are dominant; long-range colonization through dispersal is rare or absent and where local populations are basically unconnected at a regional scale (Freckleton and Watkinson 2002).

Further evidence for the lack of metapopulation structure lies in the historical records of Z. abelicea distribution for the last 300 years (Kozlowski et al. 2013), according to which no population shifts have occurred. As a consequence, it could be hypothesized that bottom-up processes, mainly related to the persistence by forceful vegetative reproduction of $Z$. $a$ belicea, are regulating the regional distribution and abundance of Z. abelicea populations and that processes at the patch level should be taken into consideration for conservation planning (Freckleton and Watkinson 2002). On the other side, this is not the case for other relict species, such as Liquidambar orientalis, where a metapopulation structure has been reported (Öztürk et al. 2008). One possible conclusion might thus be that conservation planning for relict species in the Mediterranean refugia should not be species-independent, but taxon specific.

\section{Conclusions}

On the whole, it could be reported that fine-scale spatial patterns of $Z$. abelicea indicate that processes related to the persistence of the species-to-climate changes are more complicated and multifactorial than a linear and plain view of survival in climate refugial areas.

Zelkova abelicea tolerates disturbance or track changes resulting from disturbance in the range of its distribution through morphological and reproductive plasticity, so its persistence was not only a matter of isolated enclaves in suitable climate space. Indications of plant-plant interactions, such as the assumed mutualistic relationship, further support this view, also classifying Z. abelicea as a BS species, which requires for its persistence a mutualist that is also limited by climate.

Therefore, incorporation of the aforementioned points in future conservation planning seems to be of essential priority, and we call for a shift in the attention of conservation practitioners from spatial patterns to processes which are related to the persistence of the species to climate change.

Acknowledgments We thank Vaios Kalogrias (University of Crete) for his help with GIS, we thank Robin Pakeman (Macaulay Institute) for his suggestions and we are grateful for the very constructive comments of two reviewers.

\section{References}

Almeida-Neto M, Guimaraes P, Guimarães PR, Loyola RD, Ulrich W (2008) A consistent metric for nestedness analysis in ecological systems: reconciling concept and measurement. Oikos 117:1227-1239

Araújo MB, Peterson AT (2012) Uses and misuses of bioclimatic envelope modeling. Ecology 93:1527-1539

Barnosky AD, Matzke N, Tomiya S, Wogan GOU, Swartz B, Quental TB, Marshall C, McGuire JL, Lindsey EL, Maguire KC, Mersey B, Ferrer EA (2011) Has the Earth's sixth mass extinction already arrived? Nature 471:51-57

Barrows CW, Murphy-Mariscal ML (2012) Modeling impacts of climate change on Joshua trees at their southern boundary: how scale impacts predictions. Biol Conserv 152:29-36

Beaumont LJ, Hughes L, Poulsen M (2005) Predicting species distributions: use of climatic parameters in BIOCLIM and its impact on predictions of species' current and future distributions. Ecol Modell 186:251-270

Béguinot A (1929) Illustrazioni delle filliti quaternarie dei travertini palermitani conservate nel Museo di Geologia della R. Università di Palermo. Archivio Botanico 5:143-173

Bellard C, Bertelsmeier C, Leadley P, Thuiller W, Courchamp F (2012) Impacts of climate change on the future of biodiversity. Ecol Lett 15:365-377

Bertness MD, Callaway RM (1994) Positive interactions in communities. TREE 9:191-193

Boyd A (2009) Relict conifers from the mid-Pleistocene of Rhodes, Greece. Hist Biol 21:1-15

Brooksbank K, Veneklaas EJ, White DA, Carter JL (2011) The fate of hydraulically redistributed water in a semi-arid zone eucalyptus species. Tree Physiol 31:649-658

Burnham RJ (1986) Foliar morphological analysis of the Ulmoideae (Ulmaceae) from the Early Tertiary of western North America. Palaeontogr Abteilung B 201:135-167 
Caldwell MM, Dawson TE, Richards JH (1998) Hydraulic lift: consequences of water efflux from the roots of plants. Oecologia 113:151-161

Callaway RM, Brooker RW, Choler P, Kikvidze Z, Lortie CJ, Michalet R, Paolini L, Pugnaire FI, Newingham B, Aschehoug ET, Armas C, Kikodze D, Cook BJ (2002) Positive interactions among alpine plants increase with stress. Nature 417:844-848

Connell JH (1978) Diversity in tropical rain forests and coral reefs. Science 199:1302-1309

Dawson TE (1993) Hydraulic lift and water use by plants: implications for water balance, performance and plant-plant interactions. Oecologia 95:565-574

De Paola M, Franco A, Macchia F, Forte L (1997) Plant macrofossils in Pleistocenic volcanoclastic deposit near Tursi (Basilicata). Atti Giornata di Studi in ricordo di Daria Bertolani Marchetti (Formigine, 18 maggio 1996), Aedes Muratoriana, Modena

Denk T, Grimm GW (2005) Phylogeny and biogeography of Zelkova (Ulmaceae sensu stricto) as inferred from leaf morphology, ITS sequence data and the fossil record. Bot J Linn Soc 147:129-157

Denk T, Frotzler N, Davitashvili N (2001) Vegetational patterns and distribution of relict taxa in humid temperate forests and wetlands of Georgia (Transcaucasia). Biol J Linn Soc 72:287-332

Di Pasquale G, Garfî G (1998) Evolution comparée des structures des peuplements mélangés à Quercus suber et Quercus pubescens après elimination du pâturage en forêt de Pisano (Sicile sudorientale). Ecol Mediterr 24:15-25

Di Pasquale G, Garfî G, Quézel P (1992) Sur la présence d'un Zelkova nouveau en Sicile sud-orientale (Ulmaceae). Biocosme Mésogéen 8-9:401-409

Egli B (1997) A project for the preservation of Zelkova abelicea (Ulmaceae), a threatened endemic tree species from the mountains of Crete. Bocconea 5:505-510

Elzinga CL, Salzer DW, Willoughby JW (1998) Measuring and monitoring plant populations. U.S Department of the Interior, Bureau of Land Management, Denver CO

European Commission (2007) Interpretation manual of European Union Habitats, version EUR 27, EC/DG Environment. p 142

Fazan L, Stoffel M, Frey DJ, Pirintsos S, Kozlowski G (2012) Small does not mean young: age estimation of severely browsed trees in anthropogenic Mediterranean landscapes. Biol Conserv 153:97-100

Fineschi S, Anzidei M, Cafasso D, Cozzolino S, Garfî G, Pastorelli R, Salvini D, Taurchini D, Vendramin GG (2002) Molecular markers reveal a strong genetic differentiation between two European relic tree species: Zelkova abelicea (Lam.) Boissier and Z. sicula Di Pasquale, Garfi \& Quézel (Ulmaceae). Conserv Genet 3:145-153

Fineschi S, Cozzolino S, Migliaccio M, Vendramin GG (2004) Genetic variation of relic tree species: the case of Mediterranean Zelkova abelicea (Lam.) Boissier and Z. sicula Di Pasquale, Garfî and Quézel (Ulmaceae). Forest Ecol Manag 197:273-278

Follieri M, Magri D, Sadori L (1986) Late Pleistocene Zelkova extinction in central Italy. New Phytol 103:269-273

Follieri M, Magri D, Sadori L (1989) Pollen stratigraphical synthesis from valle di Castiglione (Roma). Quat Int 3/4:1040-6182

Freckleton RP, Watkinson AR (2002) Large-scale spatial dynamics of plants: metapopulations, regional ensembles and patchy populations. J Ecol 90:419-434

Garfî G, Buord S (2012) Relict species and the challenges for conservation: the emblematic case of Zelkova sicula Di Pasquale, Garfi et Quézel and the efforts to save it from extinction. Biodivers J 3:281-296

Garfì G, Carimi F, Pasta S, Rühl J, Trigila S (2011) Additional insights on the ecology of the relic tree Zelkova sicula Di
Pasquale, Garfî et Quézel (Ulmaceae) after the finding of new population. Flora 206:407-417

Gavilán RG, Sánchez-Mata D, Escudero A, Rubio A (2002) Spatial structure and interspecific interactions in Mediterranean high mountain vegetation (Sistema Central, Spain). Isral J Plant Sci 50:217-228

Godefroid S, Piazza C, Rossi G et al (2011) How successful are plant species reintroductions? Biol Conserv 144:672-682

Gómez-Aparicio L, Zamora R, Gómez JM, Hódar JA, Castro J, Baraza E (2004) Applying plant facilitation to forest restoration in Mediterranean ecosystems: a meta-analysis of the use of shrubs as nurse plants. Ecol Appl 14:1128-1138

Gómez-Aparicio L, Gómez JM, Zamora R, Boettinger JL (2005) Canopy vs. soil effects of shrubs facilitating tree seedlings in Mediterranean montane ecosystems. J Veg Sci 16:191-198

Grimm GW, Denk T, Hemleben V (2007) Evolutionary history and systematics of Acer section Acer-a case study of low-level phylogenetics. Plant Syst Evol 267:215-253

Hampe A, Jump AS (2011) Climate relicts: past, present, future. Annu Rev Ecol Evol Syst 42:313-333

Hanski I (1991) Single-species metapopulation dynamics: concepts, models and observations. Biol J Linn Soc 42:17-38

Heikkinen RK, Luoto M, Araújo MB, Virkkala R, Thuiller W, Sykes MT (2006) Methods and uncertainties in bioclimatic envelope modelling under climate change. Prog Phys Geogr 30:751-777

Higgins MD, Higgins R (1996) A geological companion to Greece and the Aegean. Gerald Duckworth \& Co, London

Hill MO (1979) TWINSPAN-A FORTRAN program for arranging multivariate data in an ordered two-way table by classification of the individuals and attributes. Ecology and Systematics. Cornell University, Ithaca, New York

Hosmer DW, Lemeshow S (2000) Applied logistic regresssion. Wiley, New York

Jeltsch F, Moloney KA, Schurr FM, Kochy M, Schwager M (2008) The state of plant population modelling in light of environmental change. Perspect Plant Ecol Evol Syst 9:171-190

Keppel G, Van Niel KP, Wardell-Johnson GW, Yates CJ, Byrne M, Mucina L, Schut AGT, Hopper SD, Franklin SE (2012) Refugia: identifying and understanding safe havens for biodiversity under climate change. Global Ecol Biogeogr 21:393-404

Kozlowski G, Frey D, Fazan L, Egli B, Pirintsos S (2012) Zelkova abelicea. In: IUCN 2012. IUCN Red List of Threatened Species. Version 2012.2. www.iucnredlist.org. Downloaded on 8 May 2013

Kozlowski G, Frey D, Fazan L, Egli B, Bétrisey S, Gratzfeld J, Garfî G, Pirintsos S (2013) The Tertiary relict tree Zelkova abelicea (Ulmaceae): distribution, population structure and conservation status on Crete. Oryx. doi:10.1017/S0030605312001275

Levin SA (1992) The problem of pattern and scale in Ecology. Ecology 73:1943-1967

Levin SA, Paine RT (1974) Disturbance, patch formation, and community structure. PNAS 71:2744-2747

Loss S, Terwilliger LA, Peterson AC (2011) Assisted colonization: integrating conservation strategies in the face of climate change. Biol Conserv 144:92-100

Mackey RL, Currie DJ (2001) The diversity-disturbance relationship: is it generally strong and peaked? Ecology 82:3479-3492

Malcolm JR, Liu C, Neilson RP, Hansen L, Hannah L (2006) Global warming and extinctions of endemic species from biodiversity hotspots. Conserv Biol 20:538-548

McCune B, Mefford MJ (1999) Multivariate Analysis of Ecological Data. Version 4.10. MjM Software, Gleneden Beach, Oregon, USA

Médail F, Diadema K (2009) Glacial refugia influence plant diversity patterns in the Mediterranean Basin. J Biogeogr 36:1333-1345 
Mendoza I, Zamora R, Castro J (2009) A seeding experiment for testing tree-community recruitment under variable environments: implications for forest regeneration and conservation in Mediterranean habitats. Biol Conserv 142:1491-1499

Morrison LW (2013) Nestedness in insular floras: spatiotemporal variation and underlying mechanisms. J Plant Ecol. doi:10.1093/ jpe/rtt002

Öztürk M, Çelik A, Güvensen A, Hamzaoğlu E (2008) Ecology of Tertiary relict endemic Liquidambar orientalis Mill. forests. Forest Ecol Manag 256:510-518

Pearson RG, Raxworthy CJ, Nakamura M, Peterson AT (2007) Predicting species distributions from small numbers of occurrence records: a test case using cryptic geckos in Madagascar. J Biogeogr 34:102-117

Petit RJ, Hampe A, Cheddadi R (2005) Climate changes and tree phylogeography in the Mediterranean. Taxon 54:877-885

Phillips SJ, Anderson RP, Schapire RE (2006) Maximum entropy modeling of species geographic distributions. Ecol Model 190:231-259

Proulx M, Mazumder A (1998) Reversal of grazing impact on plant species richness in nutrient-poor vs nutrient-rich ecosystems. Ecology 79:2581-2592

Pulido F, Valladares F, Calleja JA, Moreno G, González-Bornay G (2008) Tertiary relict trees in a Mediterranean climate: abiotic constraints on the persistence of Prunus lusitanica at the eroding edge of its range. J Biogeogr 35:1425-1435

Quero JL, Gómez-Aparicio L, Zamora R, Maestre FT (2008) Shifts in the regeneration niche of an endangered tree (Acer opalus ssp. granatense) during ontogeny. Basic Appl Ecol 9:635-644

Randin CF, Engler R, Normand S, Zappa M, Zimmermann NE, Pearman PB, Vitoz P, Thuiller W, Guisan A (2009) Climate change and plant distribution: local models predict high elevation persistence. Global Change Biol 15:1557-1569

Richter S, Kipfer T, Wohlgemuth T, Calderón Guerrero C, Ghazoul J, Moser B (2012) Phenotypic plasticity facilitates resistance to climate change in a highly variable environment. Oecologia 169:269-279

Scholz FG, Bucci SJ, Hoffmann WA, Meinzer FC, Goldstein G (2010) Hydraulic lift in a Neotropical savanna: experimental manipulation and model simulations. Agric Forest Meteorol 150:629-639

Schwartz MW (2012) Using niche models with climate projections to inform conservation management decisions. Biol Conserv 155:149-156

Søndergaard P, Egli BR (2006) Zelkova abelicea (Ulmaceae) in Crete: floristics, ecology, propagation and threats. Willdenowia 36:317-322

Stein BA, Shaw MR (2013) Biodiversity conservation for a climatealtered future. In: Moser SC, Boykoff MT (eds) Successful adaptation to climate change: linking science and policy in a rapidly changing world. Routledge, London, pp 50-66

Stoll P, Weiner J (2001) A neighborhood view of interactions among individual plants. In: Dieckmann U, Law R, Metz JAJ (eds) The geometry of ecological interactions. Simplifying spatial complexity. Cambridge University Press, Cambridge, pp 11-27

Stork NE (2010) Re-assessing current extinction rates. Biodivers Conserv 19:357-371

Thuiller W, Lavorel S, Araújo MB, Sykes MT, Prentice C (2005) Climate change threats to plant diversity in Europe. PNAS 102:8245-8250

Thuiller W, Albert C, Araújo MB et al (2008) Predicting global change impacts on plant species' distributions: future challenges. Perspect Plant Ecol Evol Syst 9:137-152

Ulrich W, Almeida-Neto M, Gotelli NJ (2009) A consumer's guide to nestedness analysis. Oikos 118:3-17

Valiente-Banuet A, Vital A, Verdú M, Callaway RM (2006) Modern Quaternary plant lineages promote diversity through facilitation of ancient Tertiary lineages. PNAS 103:16812-16817

Valladares F (2008) A mechanistic view of the capacity of forest to cope with climate change. In: Bravo F, May VL, Jandl R, Gadow Kv (eds) Managing forest ecosystems: the challenge of climate change. Springer, Berlin, pp 15-40

Valladares F, Gianoli E (2007) How much ecology do we need to know to restore Mediterranean ecosystems? Restor Ecol 15:363-368

Valladares F, Balaguer L, Martinez-Ferri E, Perez-Corona E, Manrique E (2002) Plasticity, instability and canalization: is the phenotypic variation in seedlings of sclerophyll oaks consistent with the environmental unpredictability of Mediterranean ecosystems? New Phytol 156:457-467

Van der Wiel AM, Wijmstra TA (1987) Palynology of the lower part (78-120 m) of the core Tenaghi Philippon II, Middle Pleistocene of Macedonia, Greece. Rev Palaeob Palyno 52:73-88

Veech JA (2013) A probabilistic model for analysing species cooccurrence. Global Ecol Biogeogr 22:252-260

Vrochidou A-EK, Tsanis IK (2012) Assessing precipitation distribution impacts on droughts on the island of Crete. Nat Hazards Earth Syst Sci 12:1159-1171

Wang Y-F, Ferguson DK, Zetter R, Denk T, Garfî G (2001) Leaf architecture and epidermal characters in Zelkova, Ulmaceae. Bot J Linn Soc 136:255-265

Willis KJ, Bhagwat SA (2009) Biodiversity and climate change. Science 326:806-807

Wisz MS, Pottier J, Kissling WD et al (2013) The role of biotic interactions in shaping distributions and realised assemblages of species: implications for species distribution modelling. Biol Rev 88:15-30

Wright DH, Patterson BD, Mikkelson GM, Cutler A, Atmar W (1998) A comparative analysis of nested subset patterns of species composition. Oecologia 113:1-20

Zheng-yi W, Raven PH (eds) (2003) Zelkova. Flora of China. Vol. 5. Ulmaceae-Basellaceae, Missouri Botanical Garden Press, St. Louis 